\title{
Climatic Variability and Cause-Specific Migration in Rural and Urban India
}

\author{
Carolyn B. Reyes \\ The Pennsylvania State University \\ University Park, PA \\ cfb132@psu.edu \\ ORCID ID: 0000-0001-8252-5633
}

Brian C. Thiede

The Pennsylvania State University

University Park, PA

February 16, 2022

\section{Statements and Declarations}

No funding was received to assist with the preparation of this manuscript and the authors have no competing interests to declare that are relevant to the content of this article.

\section{Acknowledgements}

An earlier version of this paper was presented at the 2021 annual meeting of the American Sociological Association. Thiede acknowledges assistance provided by the Population Research Institute at Penn State University, which is supported by an infrastructure grant from the Eunice Kennedy Shriver National Institute of Child Health and Human Development (P2CHD041025). Thiede's work was also supported by the USDA National Institute of Food and Agriculture and Multistate Research Project \#PEN04623 (Accession \#1013257). 


\begin{abstract}
A growing literature on the demographic impacts of climate change has shown that temperature and precipitation variability disrupts migration patterns throughout the developing world. The empirical record today represents a significant improvement over what was available just a decade ago, but it is nonetheless characterized by important gaps that limit the substantive interpretation of observed patterns. In the current study of climate-related migration in India, we aim to address at least two of these limitations by analyzing the effects of climate variability on cause-specific migration and decomposing migration outcomes between rural and urban origins and destinations. We leverage data from three rounds of the Indian Socio-Economic Survey (ISES) fielded between 1983 and 1999, which provide unique details on individuals' pre- and post-migration locations and their self-reported reasons for migration. We find temperature and precipitation variability to be associated with reduced migration, particularly laborand family-related moves. The relationship between climate variability and migration outcomes is not found to vary significantly between rural and urban areas. Migration outcomes among women are found to be more sensitive to climate variability than among men, particularly for family- and marriage-related migration.
\end{abstract}

Key Words: Migration; Climate change; India; Rural; Urban; Gender 


\section{Introduction}

Climate change is having profound, if regionally-diverse impacts around the globe, resulting in rising temperatures, changes in precipitation patterns, and increasing prevalence and intensity of natural disasters such as hurricanes and typhoons (IPCC 2014). These changes are expected to have significant impacts on natural and social systems. Changes in migration patterns have been among the plausible social impacts of climate change given most attention. A burgeoning literature on climate-related migration reveals how temperature and precipitation fluctuations impact human mobility, particularly in the Global South (Fussell, Hunter, \& Gray, 2014; Mueller, Gray, \& Hopping, 2020; Sedova \& Kalkuhl, 2020). Although popular accounts of climate and migration have emphasized the likelihood of climate-induced population displacement, the existing scientific work offers a more complicated picture. Climate shocks may increase or decrease migration; and climate effects vary significantly by migrant destination, gender, socioeconomic status, and national context (Baez, Caruso, Mueller, \& Niu, 2017; BohraMishra et al., 2016; Mastrorillo et al., 2016; Sedova \& Kalkuhl, 2020). As such, the record to date robustly critiques the conventional, neo-Malthusian narratives of climate and migration.

Despite these important contributions, the climate-migration literature remains characterized by a number of open questions and non-trivial limitations. In this paper, we address one of the conceptual limitations to the existing literature: With a few notable exceptions (Gray \& Mueller, 2012a), most studies of climate and migration have been motivated by theories of labor migration (Shrestha \& Bhandari, 2007). Prior studies largely conceptualize climate-induced migration as a response to changing incentives for how much and where a household's workers are deployed in the aftermath of environmental shocks, such as the income losses associated with temperature-related reductions in crop yields or labor productivity (Cattaneo \& Peri, 2016; Iqbal 
\& Roy, 2015; Nawrotzki, DeWaard, Bakhtsiyarava, \& Ha, 2017a; Viswanathan \& Kumar, 2015). However, relatively few studies have explicitly tested this labor migration hypothesis, and there are reasons to also expect non-labor migration (e.g., marriage-related moves) to be influenced by climatic variability. ${ }^{1}$

In this study, we address this evidence gap, drawing on a dataset from the 1980s and 1990s in India to analyze the effects of climate variability on cause-specific migration. As a second main contribution, we decompose migration outcomes between rural and urban origins and destinations to evaluate the hypotheses that climate impacts on migration are focused in rural areas, which has also been commonly assumed in the literature to date. Finally, we build on a growing body of work on the gendered nature of climate impacts by assessing the ways in which climate-related migration patterns vary by sex (Bohra-Mishra et al., 2016; Gray \& Mueller, 2012b; Mastrorillo et al., 2016).

To preview our findings, our results reveal stronger effects of precipitation than temperature, with higher levels of precipitation associated with significantly less migration overall. Precipitation was also found to suppress rural out-migration, and both precipitation and temperature are associated with reduced labor migration. Finally, we find that the types of migration affected by climate variability among women differ significantly from the overall model, suggesting alternative mechanisms through which climate shocks influence women's and men's migration in the Indian context.

\footnotetext{
${ }^{1}$ This limitation may reflect data constraints. Most existing census and survey data do not allow for the disaggregation of migration by cause or type.
} 


\section{Conceptualizing and measuring climate-induced migration}

Climate variability adversely impacts many developing countries, particularly those with large shares of the population engaged in agricultural work or who are otherwise vulnerable to shocks (Cohn et al., 2017; Otto et al., 2017; Thomas \& Twyman, 2005). Temperature and precipitation fluctuations, as well as correlated natural disasters (e.g., floods), are associated with reductions in crop production, labor productivity, and other activities that undermine economic activity (Dell, Jones, \& Olken, 2014; Hsiang et al., 2017; Iqbal \& Roy, 2015; Sanabria, Calanca, Alarcón, \& Canchari, 2014). Popular narratives have stressed the possibility of large-scale population displacements from climate change. However, these predictions are not fully supported by a growing body of work using large-scale census and survey data to statistically evaluate the effects of climate variability on migration (Bohra-Mishra et al., 2016; Cattaneo \& Peri, 2016; Dallmann \& Millock, 2017; Gray, \& Bilsborrow, 2013; Gray \& Mueller, 2012; Gray \& Wise, 2016; Koubi, Spilker, Schaffer, \& Böhmelt, 2016; Mastrorillo et al., 2016; Piguet, Kaenzig, Guélat, Kaenzig RaoulKaenzig, \& Jérémie Guélat, 2018; Riosmena, Nawrotzki, \& Hunter, 2018; Sedova \& Kalkuhl, 2020; Viswanathan \& Kavi Kumar, 2015).

Indeed, the evidence from existing empirical studies points to a much more nuanced and complicated picture. The direction and magnitude of temperature and precipitation effects on migration varies considerably across space and time (Dallmann \& Millock, 2017; Gray \& Wise, 2016; Mastrorillo et al., 2016; Thiede et al., 2016). For example, Gray and Wise (2016) found that higher temperatures have differential effects on migration across five countries in Africa over a six-year period in the early 2000s. While temperature exposures were positively associated with migration in Kenya and Uganda, higher temperatures reduced migration in 
Burkina Faso and had no association with migration in Nigeria and Senegal. ${ }^{2}$ Likewise, Mueller and colleagues' (2020) study of climate variability and migration in Botswana, Kenya, and Zambia documents inconsistent precipitation effects over 22 years, with rainfall reducing migration in Botswana and Kenya but increasing migration in Zambia. In South America, Thiede, Gray and Muller (2016) found temperature to be a more significant driver of migration compared to precipitation between 1970-2011, while documenting considerable variation in effects across the eight countries in their sample. In a final example, Gray, Hopping, and Mueller (2020) found that the effects of temperature on migration in China varied across their 1989-2011 study period, with displacing effects of high temperatures weakening over time. Cross-national and longitudinal studies such as these demonstrate that the relationship between climate variability and migration varies across and within countries, preventing universal claims about the effects of temperature or precipitation variability and migration. ${ }^{3}$

The studies above highlight the spatial and temporal variation in climate effects that has been detected within studies, when the same measures and methods are applied to different contexts. Such comparisons are unlikely to be confounded by methodological differences. Nonetheless, one could also point to considerable variation in temperature and precipitation effects across studies. For example, a number of recent analyses in Bangladesh and Indonesia found positive effects of temperature variability on migration, while rainfall variability had weak or non-significant correlations (Bohra-Mishra, Oppenheimer, \& Hsiang, 2014; Call, Gray, Yunus, \& Emch, 2017). In Indonesia, temperature was found to have the most consistent effect on migration compared to precipitation and sudden-onset natural disasters (e.g., earthquakes, landslides) (Bohra-Mishra et al., 2014). In Bangladesh, migration was found to decline after

\footnotetext{
${ }^{2}$ Precipitation was found to have minimal and inconsistent effects across all countries in this study.
} 
sustained excess rainfall and drought, while rising temperatures were associated with increased migration (Call et al., 2017). Others have found fluctuations in precipitation to be predictors of migration among particular sub-groups (Mastrorilo et al., 2016). For example, in South Africa, Black and low-income individuals were found to be the most likely to migrate in response to diminished rainfall and higher temperatures (Mastrorillo et al., 2016). Variation in the correlation between climate variability and migration suggests migrants in different contexts may have a range of motives for migrating in response to environmental change.

While the empirical record on climate-related migration has been mixed, the conceptual model behind most previous research is widespread, presuming climatic variability affects migration by way of changes in agricultural production and other determinants of economic welfare (Bylander, 2015; Chen \& Mueller, 2018; Iqbal \& Roy, 2015; Viswanathan et al., 2015). These economic impacts are assumed - in turn - to shape migration by incentivizing labor migration or changing the stock of resources needed to fund labor migration (Cattaneo \& Peri, 2016; Nawrotzki \& Bakhtsiyarava 2017). That is, migration is employed as a household livelihood diversification strategy in response to an environmental change(s) that strains household economic well-being. For example, in a study of internal migration in Mexico, rural out-migration was found to decline as the number of hot months increased, but it increased with each additional month of drought (Nawrotzki et al., 2017). The authors argue that the initial heat increases were associated with improved crop yields, thus reducing the need to migrate in search of additional income; but drought diminished agricultural returns and pushed migrants from rural areas. Thus, migrants are presumed to respond to household economic uncertainty associated with climate impacts on agricultural production by seeking work elsewhere, employing migration as a livelihood strategy in response to increasing agricultural stress. Another study in 
Nepal explicitly evaluated the labor-migration response to environmental insecurity, measured by access to firewood (Shrestha \& Bhandari, 2007). Restricting their sample exclusively to labor migrants, the authors found reduced forest resources to be significantly associated with laborrelated moves, regardless of the migrant's destination. In these and other cases, much (but not all) prior work has either implicitly or explicitly ignored the response of non-labor migration to environmental change. ${ }^{4}$ Our work aims to fill this gap by testing other possible mechanisms through which environmental variability impacts migration.

Prior research has also made important assumptions about the places that environmental shocks are likely to affect migration. Given the potentially large livelihood impacts of climate variability among agriculturally dependent communities, much of the existing literature on climate-related migration concentrates on rural, agriculturally dependent populations in the developing world. The effects of climate on agricultural yields and income are assumed to be one of the primary mechanism through which climate variability incentivizes labor migration. For example, in Bangladesh, agricultural productivity losses associated with rainfall variability were found to be significantly associated with district-level net out-migration (Iqbal \& Roy, 2015). The authors explicitly frame out-migration as labor migration, as it operates through economic insecurity among agriculturally-dependent households. Another example in India found the decline in agricultural output resulting from climate change was associated with increased rural out-migration from agricultural producing regions, again presuming migrants were motivated to search for alternate income generating labor activities (Viswanathan \& Kavi Kumar, 2015). Finally, Cattaneo and Peri (2016) assessed international out-migration and internal rural-to-urban migration in 115 middle- and low-income countries over 40 years in response to agricultural

\footnotetext{
${ }^{4}$ A similar point was also made in a recent simulation by Entwisle et al. (2020), which noted the absence of lifecourse perspectives in the climate-migration literature (Entwisle, Williams, \& Verdery, 2020).
} 
impacts of climate variability. Higher temperatures were associated with increased internal and international out-migration in middle-income countries, but heat reduced probabilities of migration in low-income countries, suggesting a moderating effect of income. The authors suggest that these findings reveal agriculturally-dependent households in middle-income countries to be more likely to send migrants to supplement household incomes, while households in more impoverished nations are economically constrained and unable to respond to economic pressures associated with climate change using migration. What remains largely understudied and rarely observed are the reported motives of migrants themselves in the context of climate variability, leaving only speculation and presumptions about migrant decision-making processes.

There are plausible reasons to expect other forms of migration to be influenced by climate. Within the climate-labor migration framework, migration not associated with labor such as for marriage or other family-related reasons - are not presumed to be affected by climate conditions. However, climate change and associated environmental stress is thought to have a number of demographic implications around childbearing, marriage, and health, which in turn influence migration probabilities, abilities, and decision-making (Ezra, 2001). Indeed, socioeconomic factors such as gender, wealth, religion, and castes have been found to impact migration distance, destination, and reported motives in India (Dallman and Millock, 2017). For example, data from the Indian Census in 1991 and 2001 reveal women to be less likely to report labor or business opportunities as their stated reasons to migrate compared to men (Dallmann \& Millock, 2017). While limited studies have explicitly tested the reported cause of migration in response to climate change in this context, some evidence suggests that variation by gender is likely (Gray \&Mueller, Rosenweig \& Stark, 1989). In one of few examples, Gray and Mueller (2012) explicitly tested the cause of migration in response to drought in Ethiopia, disaggregating 
findings by gender. Causes of migration were found to vary by both gender and wealth: landpoor men from rural areas were more likely to migrate for labor in response to drought, while drought-affected women were less likely to make marriage-related moves, indicating gendered patterns of resource needs that are impacted by a changing environment (Gray and Mueller, 2012). Likewise, in an influential paper, Rosenzweig and Stark (1989) found that longer-distance migration for marriage in India was associated with higher household income risks, suggesting agriculture-dependent households vulnerable to economic fluctuations due to environmental variability may respond with shifts in marriage-related migration. Finally, evidence suggests that rising temperatures and precipitation variability are associated with civil unrest and social instability, which may also influence migrant decisions above and beyond their labor market impacts (Bohra-Mishra et al., 2014; S. M. Hsiang, Meng, \& Cane, 2011).

Given the state of existing empirical evidence, additional research is needed to evaluate the types of migration that are affected by climate variability and its second-order socioeconomic impacts. Do climate exposures primarily affect labor migration, or are other types of migration also affected? We aim to evaluate this question empirically by linking climate records with survey data on spatial mobility and cause of migration in the Indian context. We examine the respective associations between exposure to temperature and precipitation anomalies and moves associated with work, marriage, other family obligations, and other causes. We also address key assumptions in the existing climate-migration literature by evaluating whether these associations vary by gender and rurality. 


\section{Data and Methodology}

We draw on individual-level demographic data from the Indian Socio-Economic Survey (ISES), which is a cross-national employment survey implemented by the Government of India's National Sample Survey Organization. We accessed ISES records through the IPUMSInternational database (Minnesota Population Center 2018). We pool records from 1983, 1987, and 1999, which are the only available rounds that include the full details of cause-specific migration that we leverage in this study. We restrict our sample to individuals aged 15-49 years to exclude ages at which migration is rare. Our final analytic sample includes 933,307 observations. We apply sampling weights provided by IPUMS throughout the analysis.

Our focus on India is merited given its large population size - currently over 1.3 billion and both previous and projected exposure to adverse environmental conditions. India is particularly vulnerable to shocks related to climate change given the large rural population $(65 \%$ in 2020) and reliance on the agricultural sector (much of it rainfed), which employs over 50 percent of the rural Indian population (Dallmann \& Millock, 2017; Rao et al., 2015; Taraz, 2018; World Bank, 2020). Average temperatures in India have been on the rise and are projected to continue the upward trajectory (Taraz, 2018). Although the sub-continent is large and ecologically diverse, evidence suggests that high temperatures and other climatic changes will have adverse effects on crops, agriculture, and many social and demographic outcomes across much of the country (Bush et al., 2011; Davis, Chhatre, Rao, Singh, \& DeFries, 2019; Lopalo, Kuruc, \& Spears, 2019).

We link our demographic data to historical climate records at the state level, which is the first-level subnational unit in India and the highest resolution that we can identify individuals' places of current and previous residence using these data (see map in Figure 1). We use monthly temperature and precipitation records for 1951-2013 from the Climate Research Unit Time Series 
(CRU TS) (Harris, Jones, Osborn, \& Lister, 2014). CRU TS is a widely used source of highresolution $\left(0.5^{\circ}\right)$ climate data produced by interpolating meteorological records from over 4000 weather stations globally. Using the IPUMS-Terra interface (Ruggles et al. 2018), we extract monthly mean temperature and precipitation as spatial means and use these data to measure climate anomalies (see below).

(Figure 1: State-level boundary map of India utilized for analysis

Our outcome of interest is migration. We define individuals as migrants if they have resided in their current place of residence for one year or less (i.e., less than 24 months). Our main analyses focus on all migrants, regardless of the distance they moved..$^{5}$ We operationalize migration in three ways throughout the study. First, we construct a binary indicator of whether an individual moved within the two-year migration interval defined above. Second, we differentiate between rural- and urban-bound migrants, using the same definition of migration as the first measure and using the rural and urban classifications included in the ISES data to define destination type. ${ }^{6}$ Third, we disaggregate migrants according to cause using a five-category variable contrasting (1) non-migrants with migrants who moved due to (2) work, (3) marriage, (4) other family obligations, and (5) other causes.

Our predictors of interest are temperature and precipitation variability. We operationalize these variables using measures of average state-level temperature and precipitation over the 24 months prior to the survey, standardized over all other 24-month intervals in the 1951-2013 climate

\footnotetext{
${ }^{5}$ Of these moves, 95 percent were intra-state and 5 percent were inter-state migration moves.

${ }^{6}$ According to the documentation provided by IPUMS, the survey defines urban areas as "towns (places with municipal corporation, municipal area committee, town committee, notified area committee or cantonment board); also, all places having 5,000 or more inhabitants, a density of not less than 1,000 persons per square mile or 400 per square kilometer, pronounced urban characteristics and at least three fourths of the adult male population employed in pursuits other than agriculture."
} 
history (i.e., z-scores). These climate anomalies have the advantage of being locally meaningful, since they capture deviations from the local normal (i.e., typical mean and variability) that social and agricultural systems are likely to be adapted around. Perhaps for this reason, anomalies have been shown to be stronger predictors of demographic outcomes than raw values (Gray \& Wise, 2016). We assign individuals the climate values for their state of residence at the start of the migration interval using state of current residence for non-migrants and state of prior residence for migrants. The approach for the latter assumes that individuals have moved between states no more than once during the migration interval, which is plausible given the short interval and low rates of inter-state migration in India.

We measure the climate effects of interest using a series of logistic regression models, which treat out-migration as a function of climate exposures, net of controls and both state and period fixed effects. Binary outcome models are used to predict individuals' overall migration status, and multinomial models are used to estimate models of migration-by-destination type (i.e., rural vs. urban destinations) and cause-specific migration. All models control for demographic correlates of migration, including age, gender, education, religion, and rural (urban) residence (see Table 1 for a summary). State fixed effects control for all state-level characteristics that may confound climate exposures and migration so long as they are time invariant, while period fixed effects account for inter-survey changes that are common across the entire sample. Standard errors are clustered on the state of residence at baseline, which corresponds to the level at which our exposure variables are measured (Abadie, Athey, Imbens, \& Wooldridge, 2017).

(Table 1) 


\section{Results}

\section{All-cause migration}

We begin by estimating the association between climate exposures and a binary indicator of any migration, regardless of type or cause. We estimate models assuming linear climate effects and also allowing climate effects to vary non-linearly. Our preferred specification includes quadratic terms for both temperature and precipitation (see Table 8 in the appendix for other results). We find a statistically significant association between precipitation and migration, with high levels of precipitation associated with reductions in the probability of migration (Table 2). This relationship operates in a non-linear manner, with the most meaningful declines in migration occurring when precipitation levels are much above average. To assist with the interpretation of these estimates, we plot the predicted probability of migration across a range of precipitation exposures while holding all other variables at their means (Figure 2). The predicted probability of migration decreases from a point estimate of -0.001 under average precipitation to -0.004 when precipitation is two standard deviations above normal. In contrast, the predicted probability of migration increases to 0.003 under exceptionally dry periods, when precipitation is two standard deviations below normal. While migration in India is quite rare in absolute terms, precipitation exposures clearly have substantively large relative effects. Contrary to these findings regarding precipitation, the joint effect of the temperature terms is not statistically significant and therefore not a meaningful predictor of migration as defined here.

(Table 2)

(Figure 2) 


\section{All-cause migration by origin and destination type}

Our next model examines rural-urban differences in climate-related migration. One common but largely untested argument in the climate-migration literature is that rural populations are more vulnerable to displacement than their urban counterparts, with some further anticipating climateinduced flows from rural to urban areas (Viswanathan et al., 2015). We explicitly evaluate this hypothesis in the regression model reported in Table 3, which disaggregates migration between rural and urban destinations and includes climate-by-origin type interaction terms to test for differences in effects between rural and urban origins. Among residents of urban areas, temperature is negatively associated with out-migration to rural areas, while precipitation is not a significant predictor of urban-rural migration. Estimated temperature effects are strongest at the upper end of the temperature distribution. An increase in temperature from average to two standard deviations above average is associated with a 0.003 -point reduction in the predicted probability of urban-rural migration (from -0.001 to -0.004). In contrast, temperature is not a significant predictor of urban-urban migration. However, precipitation is negatively associated with out-migration from urban to other urban areas, which is consistent with the pattern detected in the overall model. An increase in precipitation from $\mathrm{z}=0$ to $\mathrm{z}=2$ is associated with a 0.004 -point reduction in the predicted probability of urban-urban migration, from -0.000 to -0.004 .

We also measured the effects of climate variability on out-migration from rural areas (See Table 9 in Appendix for estimates of net effects among rural residents). Similar to patterns identified among urban residents, temperature is found to be associated with reduced rural-rural migration and precipitation is associated with declines in rural-urban migration. An increase in temperature from 0 to 2 standard deviations above the mean is associated with 0.003 -point reduction in the predicted probability of rural-rural migration (from -0.001 to -0.004). An increase 
in precipitation z-scores from 0 to 2 is associated with a reduced predicted probability of migration from -0.000 to -0.004 points from rural to urban areas.

(Table 3)

\section{Cause-specific estimates}

We next evaluate whether the effects of temperature and precipitation vary by the type of migration, differentiating between labor migration, family-related moves, and marriage migration (Table 4). Consistent with the labor migration hypothesis that has been common in the literature to date, we find that labor-related moves are most sensitive to climate variability among the outcomes we consider. Both temperature and precipitation are significant predictors of migration. A change in precipitation z-scores from 1 below to 1 above average results in a 0.002-point decline in the predicted probability of migration (from 0.001 to -0.001 ). Likewise, a change in temperature $\mathrm{z}$-scores from $\mathrm{z}=-2$ to $\mathrm{z}=2$ results in a 0.004 -point decline in the predicted probability of migration (from 0.002 to -0.002 ).

Temperature is also a statistically significant predictor of family-related moves, and this relationship takes a similar form to the relationship between temperature and labor-related moves. For example, temperature increases from $\mathrm{z}=0$ to $\mathrm{z}=2$ is associated with a 0.001 -point decline in the predicted probability of migration, from 0.000 to -0.001 . Precipitation exposures are not found to be statistically associated with family-related moves. It is important to note that family-related moves are defined as those following a parent or income-earning member of the family, including moves that occur because a family member is changing jobs. In other words, family-related moves suggest migration by an entire household in which the individual is embedded. Therefore, familyrelated migration may indicate more permanent migration in which entire household relocates, 
while labor- and marriage-related migration are associated with individual-level migration that may reflect household need (Massey, 1999).

Finally, we find that marriage-related moves and migration by "other" causes are not statistically associated with either temperature or precipitation overall. The analysis of marriagerelated moves notably contrasts with the findings from Rosenzweig and Stark (1989), who previously found an association between household-level economic insecurity and longer distance marriage migration in rural India. One possible explanation is that our study captures shifting patterns in marriage arrangements in the years after Rosezweig and Stark's study that are captured in our data. Alternatively, the aggregate migration-by-cause data may disguise gender variation in migratory responses to climate variability. Next, we address the later possibility by assessing migration outcomes and destinations by gender.

(Table 4)

\section{Gender and climate-related migration}

Given significant differences found in prior studies assessing climate-related migration, we conduct a final set of analyses that assess gendered differences in all-cause migration (Table 5), migration between rural and urban areas (Table 6), and migration by cause (Table 7). To facilitate interpretation, Figure 3 displays predicted probabilities of migration for different migration outcomes. All-cause migration for women is found to decline linearly as temperatures increase. An increase from 2 standard deviations below average to normal temperatures $(z=0)$ results in a 0.009-point decline in the predicted probability of migration for women (from 0.005 to -0.004 ). Migration to rural areas is found to significantly decline among women as temperatures increase.

For instance, a change in temperature from $\mathrm{z}=0$ to $\mathrm{z}=2$ is associated with a 0.004 -point decline 
in predicted probabilities for women migrating from urban-rural areas (from - 0.003 to -0.007). For both marriage and family-related migration, women's probabilities of migration are inversely associated with temperature. For example, an increase in temperature z-scores 2 below average to $\mathrm{z}=2$ above average is associated with a 0.006 -point decrease (from 0.003 to -0.003 ) in marriagerelated migration. Family-related migration among women declines from 0.000 to -0.003 as temperatures increase from average $(\mathrm{z}=0)$ to 2 standard deviations above the mean. In contrast, the odds of family- or marriage-related migration among men do not vary by temperature. Precipitation is found to have divergent impacts on marriage-related migration among men and women: Women are predicted to be significantly less likely to migrate for marriage when precipitation is above average, while men are significantly more likely to experience marriagerelated moves in such cases. Combined, these findings suggest alternate mechanisms through which climate variability impacts migration for men and women in the Indian context.

(Table 5)

(Table 6)

(Table 7)

(Figure 3)

\section{Discussion and Conclusions}

Climatic variability, primarily measured by rainfall and temperature fluctuations, has been found to have broad impacts on migration patterns around the globe (Bohra-Mishra et al., 2016; Cattaneo \& Peri, 2016; Dallmann \& Millock, 2017; Gray, \& Bilsborrow, 2013; Gray \& Mueller, 2012; Gray \& Wise, 2016; Koubi, Spilker, Schaffer, \& Böhmelt, 2016; Mastrorillo et al., 2016; Piguet et al., 2018; Riosmena et al., 2018; Sedova \& Kalkuhl, 2020; Viswanathan \& Kavi Kumar, 2015). In our study, we explicitly test hypotheses about the types of migration 
influenced by climatic variability and rural-urban differences in such migratory patterns, addressing important conceptual and empirical gaps in the climate-migration literature and offering new evidence about the impact of climate variability on migration in the Indian context. We estimate regression models to measure the associations between climate exposures and allcause migration and find precipitation to be significantly associated with a decline in migration, particularly when rainfall levels are well above average (e.g., $\mathrm{z} \geq 2$ ). This finding is consistent with prior work that suggest rainfall shocks and fluctuations restrict migration in some contexts.

Residents of rural areas are often presumed to be more sensitive to climate variability in the existing climate-migration literature, given the reliance on climate-sensitive livelihoods such as agriculture or pastoralism (Bylander, 2015; Chen \& Mueller, 2018; Iqbal \& Roy, 2015; Viswanathan et al., 2015). With a large share of the population engaged in agricultural work in India, climate variability may have implications for agricultural viability, which in turn may influence rural out-migration (Dallmann \& Millock, 2017; Taraz, 2018). We explicitly test for differences in climate-related migration between rural and urban areas, finding temperature to be associated with reduced rural out-migration to other rural areas, and precipitation to be associated with reduced rural-to-urban migration. Consistent with the overall model, excess precipitation works to suppress migration to urban areas, while temperature reduced migration between rural areas. Consistent with prior studies examining climatic impacts on agricultural output (Iqbal \& Roy, 2015; Viswanathan \& Kavi Kumar, 2015), we find evidence of increased rural out-migration in response to declines in precipitation and associated drought conditions. However, consistent with Cattaneo and Peri's (2016) study, our findings suggest climate variability may act to restrict migration, possibly by impacting household incomes and ability to fund migration. Importantly, we also do not find statistically significant differences in the effects 
of climate variability on urban- and rural-bound migration between rural and urban origins. These results demonstrate that the spatial mobility of urban populations may also be influenced by environmental changes, a possibility that in our view has been underappreciated to date.

Climate-related migration has often been conflated with labor migration within the existing literature in this field. We contribute to the limited work explicitly testing this laborclimate migration hypothesis by assessing climate-related migration by reported cause of migration. Consistent with the climate-labor migration hypothesis, we find climate variability to have the strongest impact among labor migrants. However, we find that high precipitation and temperatures are both associated with reduced labor migration, suggesting a constraining effect of climate variability. In addition, we find temperature to be significantly associated with declines in family-related migration. Finally, in contrast to Rosenweig and Stark's (1989) findings from India and evidence elsewhere (Gray \& Mueller, 2012c), we find no significant effect of climate variability on marriage-related migration. This may suggest that marriagerelated migration is less sensitive to climatic impacts on household livelihoods during the period we study.

Finally, given prior studies demonstrating gender-related differences in migration and cause of migration (Gray \&Mueller, Rosenweig \& Stark, 1989), we construct a series of models interacting gender with climate variables. We find temperature variability to be associated with reductions in our measure of all-cause migration for women, regardless of destination or cause. Diverging from the overall model, precipitation is not found to have an impact on migration for women, suggesting different mechanisms through which climatic variability influence migration by sex. In addition, we find women are more likely to migrate in response to higher temperatures, particularly to urban areas. Finally, we find that temperature exposures reduce 
women's likelihood of family-related motives and marriage-related moves. These findings offer some support for the climate-labor migration hypothesis but suggest women and men may migrate for different reasons in response to climate variability.

Our study is subject to a number of important limitations. First, the data used for this analysis are from the 1980s and 1990s in India. India has experienced major social, economic, and environmental changes in the subsequent decades. Research using more recent census data suggests that climatic variability continues to influence migration in India (Dallmann \& Millock, 2017; Viswanathan et al., 2015). These studies are limited, however, in that they do not include the details about rural or urban origin and type of migration. Updated efforts to collect such data are needed to better disentangle relationships between climate variability and migration in this context. Second, state-level climate variables may mask heterogeneity in the environmental conditions that individuals were exposed to. This is a necessary limitation of the data - a tradeoff with the data's information on place of origin and cause - but underlines the importance of including higher-resolution geographic identifiers in datasets. Despite these limitations, this study highlights the need to explicitly test key hypotheses about which populations are most vulnerable to climate shocks and the mechanisms that drive climate-related behavioral changes. Results from this study suggest that disaggregation by gender and cause of migration - whenever possible - reveal important variation in migration outcomes in response to climate variability. Finally, future work employing qualitative research approaches is needed to determine the underlying mechanisms that drive differentiation between women and men's migration and causes of migration in response to a changing climate. 


\section{References}

Abadie, A., Athey, S., Imbens, G. W., \& Wooldridge, J. (2017). When Should You Adjust Standard Errors for Clustering-*. ArXiv.

Baez, J., Caruso, G., Mueller, V., \& Niu, C. (2017). Heat exposure and youth migration in Central America and the Caribbean. American Economic Review, 107(5), 446-450. https://doi.org/10.1257/aer.p20171053

Bohra-Mishra, P., Oppenheimer, M., Cai, R., Feng, S., \& Licker, R. (2016). Climate variability and migration in the Philippines. Population and Environment, 38(3), 286-308. https://doi.org/10.1007/s11111-016-0263-x

Bohra-Mishra, P., Oppenheimer, M., \& Hsiang, S. M. (2014). Nonlinear permanent migration response to climatic variations but minimal response to disasters. Proceedings of the National Academy of Sciences, 111(27), 9780-9785. https://doi.org/10.1073/pnas.1317166111

Bush, K. F., Luber, G., Kotha, S. R., Dhaliwal, R. S., Kapil, V., Pascual, M., ... Hu, H. (2011). Impacts of climate change on public health in India: Future research directions. Environmental Health Perspectives. https://doi.org/10.1289/ehp.1003000

Bylander, M. (2015). Depending on the Sky: Environmental Distress, Migration, and Coping in Rural Cambodia. International Migration, 53(5), 135-147. https://doi.org/10.1111/imig.12087

Call, M. A., Gray, C., Yunus, M., \& Emch, M. (2017). Disruption, not displacement: Environmental variability and temporary migration in Bangladesh. Global Environmental Change, 46(August), 157-165. https://doi.org/10.1016/j.gloenvcha.2017.08.008

Cattaneo, C., \& Peri, G. (2016). The migration response to increasing temperatures. Journal of Development Economics, 122, 127-146. https://doi.org/10.1016/j.jdeveco.2016.05.004

Chen, J., \& Mueller, V. (2018). Coastal climate change, soil salinity and human migration in Bangladesh. Nature Climate Change. https://doi.org/10.1038/s41558-018-0313-8

Cohn, A. S., Newton, P., Gil, J. D. B., Kuhl, L., Samberg, L., Ricciardi, V., ... Northrop, S. (2017). Smallholder Agriculture and Climate Change. Annual Review of Environment and Resources, 42, 347-375. https://doi.org/10.1146/annurev-environ-102016-060946

Dallmann, I., \& Millock, K. (2017). Climate variability and inter-state migration in India. CESifo Economic Studies, 63(4), 560-594. https://doi.org/10.1093/cesifo/ifx014

Davis, K. F., Chhatre, A., Rao, N. D., Singh, D., \& DeFries, R. (2019). Sensitivity of grain yields to historical climate variability in India. Environmental Research Letters, 0-11.

Dell, M., Jones, B. F., \& Olken, B. A. (2014). What do we learn from the weather? The new climateeconomy literature. Journal of Economic Literature, 52(3), 740-798. https://doi.org/10.1257/jel.52.3.740

Entwisle, B., Williams, N., \& Verdery, A. (2020). Climate change and migration: New insights from a dynamic model of out-migration and return migration. American Journal of Sociology, 125(6), 1469-1512. https://doi.org/10.1086/709463

Ezra, M. (2001). Demographic responses to environmental stress in the drought- and famine-prone areas of northern Ethiopia. International Journal of Population Geography, 7(4), 259-279.

https://doi.org/10.1002/ijpg.226 
Fussell, E., Hunter, L. M., \& Gray, C. L. (2014). Measuring the environmental dimensions of human migration: The demographer's toolkit. Global Environmental Change, 28(1), 182-191. https://doi.org/10.1016/j.gloenvcha.2014.07.001

Gray, C., \& Bilsborrow, R. (2013). Environmental Influences on Human Migration in Rural Ecuador. Demography, 50, 1217-1241. https://doi.org/10.1007/s13524-012-0192-y

Gray, C., Hopping, D., \& Mueller, V. (2020). The changing climate-migration relationship in China, 1989-2011. Climatic Change, 160(1), 103-122. https://doi.org/10.1007/s10584-020-02657-x

Gray, C., \& Mueller, V. (2012a). Drought and Population Mobility in Rural Ethiopia. World Development, 40, 134-145. https://doi.org/10.1016/j.worlddev.2011.05.023

Gray, C., \& Mueller, V. (2012b). Drought and Population Mobility in Rural Ethiopia. World Development, 40(1), 134-145. https://doi.org/10.1016/j.worlddev.2011.05.023

Gray, C., \& Mueller, V. (2012c). Drought and Population Mobility in Rural Ethiopia. World Development, 40(1), 134-145. https://doi.org/10.1016/j.worlddev.2011.05.023

Gray, C., \& Wise, E. (2016). Country-specific effects of climate variability on human migration. Climatic Change, 135, 555-568. https://doi.org/10.1007/s10584-015-1592-y

Harris, I., Jones, P. D., Osborn, T. J., \& Lister, D. H. (2014). Updated high-resolution grids of monthly climatic observations - the CRU TS3.10 Dataset. International Journal of Climatology, 34(3), 623642. https://doi.org/10.1002/joc.3711

Hsiang, S., Kopp, R., Jina, A., Rising, J., Delgado, M., Mohan, S., ... Houser, T. (2017). Estimating economic damage from climate change in the United States. Science, 356(6345), 1362-1369. https://doi.org/10.1126/science.aal4369

Hsiang, S. M., Meng, K. C., \& Cane, M. A. (2011). Civil conflicts are associated with the global climate. Nature, 476(7361), 438-441. https://doi.org/10.1038/nature10311

Iqbal, K., \& Roy, P. K. (2015). Climate Change, Agriculture and Migration: Evidence From Bangladesh. Climate Change Economics, 06(02), 1550006. https://doi.org/10.1142/s2010007815500062

Koubi, V., Spilker, G., Schaffer, L., \& Böhmelt, T. (2016). The role of environmental perceptions in migration decision-making: evidence from both migrants and non-migrants in five developing countries. Population and Environment, 38(2), 134-163. https://doi.org/10.1007/s11111-016-0258-7

Lopalo, M., Kuruc, K., \& Spears, D. (2019). Quantifying India's Climate Vulnerability. India Policy Forum (Vol. 15).

Massey, D. S. (1999). Why Does Immigration Occur? A Theoretical Synthesis. In C. Hirschman, P. Kasinitz, \& J. DeWind (Eds.), The Handbook of International Migration: The American Experience. (pp. 34-52). New York: Russel Sage Foundation. Retrieved from http://ezproxy.library.uvic.ca/login?url=http://search.ebscohost.com/login.aspx?direct=true\&db=psy h\&AN=2012-99170-073\&site=ehost-live \&scope=site

Mastrorillo, M., Licker, R., Bohra-Mishra, P., Fagiolo, G., Estes, L. D., \& Oppenheimer, M. (2016). The influence of climate variability on internal migration flows in South Africa. Global Environmental Change, 39, 155-169. https://doi.org/10.1016/j.gloenvcha.2016.04.014

Morrissey, J. W. (2013). Understanding the relationship between environmental change and migration: The development of an effects framework based on the case of northern Ethiopia. Global Environmental Change, 23, 1501-1510. https://doi.org/10.1016/j.gloenvcha.2013.07.021 
Mueller, V., Gray, C., \& Hopping, D. (2020). Climate-Induced migration and unemployment in middleincome Africa. Global Environmental Change, 65(October), 102183.

https://doi.org/10.1016/j.gloenvcha.2020.102183

Nawrotzki, R. J., DeWaard, J., Bakhtsiyarava, M., \& Ha, J. T. (2017a). Climate shocks and rural-urban migration in Mexico: exploring nonlinearities and thresholds. Climatic Change, 140(2), 243-258. https://doi.org/10.1007/s10584-016-1849-0

Nawrotzki, R. J., DeWaard, J., Bakhtsiyarava, M., \& Ha, J. T. (2017b). Climate shocks and rural-urban migration in Mexico: exploring nonlinearities and thresholds. Climatic Change, 140(2), 243-258. https://doi.org/10.1007/s10584-016-1849-0

Otto, I. M., Reckien, D., Reyer, C. P. O., Marcus, R., Le Masson, V., Jones, L., ... Serdeczny, O. (2017). Social vulnerability to climate change: a review of concepts and evidence. Regional Environmental Change, 17(6), 1651-1662. https://doi.org/10.1007/s10113-017-1105-9

Piguet, E., Kaenzig, R., Guélat, J., Kaenzig RaoulKaenzig, R., \& Jérémie Guélat, U. (2018). The uneven geography of research on Benvironmental migration ${ }^{\wedge}$. Population and Environment, 39, 357-383. https://doi.org/10.1007/s11111-018-0296-4

Rao, C. S., Lal, R., Prasad, J. V. N. S., Gopinath, K. A., Singh, R., Jakkula, V. S., ... Virmani, S. M. (2015). Potential and challenges of rainfed farming in India. Advances in Agronomy (Vol. 133). Elsevier Ltd. https://doi.org/10.1016/bs.agron.2015.05.004

Riosmena, F., Nawrotzki, R., \& Hunter, L. (2018). Climate Migration at the Height and End of the Great Mexican Emigration Era. Population and Development Review, 44(3), 455-488. https://doi.org/10.1111/padr.12158

Rosenzweig, M. R., \& Stark, O. (1989). Consumption Smoothing, Migration, and Marriage : Evidence from Rural India. Journal of Political Economy, 97(4), 905-926.

Sanabria, J., Calanca, P., Alarcón, C., \& Canchari, G. (2014). Potential impacts of early twenty-first century changes in temperature and precipitation on rainfed annual crops in the Central Andes of Peru. Regional Environmental Change, 14(4), 1533-1548. https://doi.org/10.1007/s10113-0140595-y

Sedova, B., \& Kalkuhl, M. (2020). Who are the climate migrants and where do they go ? Evidence from rural India q. World Development, 129, 104848. https://doi.org/10.1016/j.worlddev.2019.104848

Shrestha, S. S., \& Bhandari, P. (2007). Environmental security and labor migration in Nepal. Population and Environment, 29(1), 25-38. https://doi.org/10.1007/s11111-007-0059-0

Taraz, V. (2018). Can farmers adapt to higher temperatures? Evidence from India. World Development, 112, 205-219. https://doi.org/10.1016/j.worlddev.2018.08.006

Thiede, B., Gray, C., \& Mueller, V. (2016). Climate variability and inter-provincial migration in South America, 1970-2011. https://doi.org/10.1016/j.gloenvcha.2016.10.005

Thomas, D. S. G., \& Twyman, C. (2005). Equity and justice in climate change adaptation amongst natural-resource-dependent societies. Global Environmental Change, 15, 115-124. https://doi.org/10.1016/j.gloenvcha.2004.10.001

Viswanathan, B., Kavi Kumar, K. S., \& Kumar, K. S. K. (2015). Weather, agriculture and rural migration: Evidence from state and district level migration in India. Environment and Development Economics, 20(4), 469-492. https://doi.org/10.1017/S1355770X1500008X 
World Bank. (2020). Rural population (\% of total population) - India, Indonesia| Data. Retrieved February 16, 2022, from https://data.worldbank.org/indicator/SP.RUR.TOTL.ZS?locations=INID\&view=chart 
Table 1: Descriptive Statistics

\begin{tabular}{|c|c|c|c|c|}
\hline & Mean / Proportion & SD & Min & Max \\
\hline Average temperature, 24 months & -0.161 & 0.732 & -2.540 & 1.673 \\
\hline Average z-score, 24 months & -0.227 & 0.786 & -2.982 & 1.459 \\
\hline \multicolumn{5}{|l|}{ Migration binary } \\
\hline Non-migrant & 0.966 & - & 0 & 1 \\
\hline Migrant & 0.034 & - & 0 & 1 \\
\hline \multicolumn{5}{|l|}{ Cause of migration } \\
\hline No migration & 0.966 & - & 0 & 1 \\
\hline Work & 0.008 & - & 0 & 1 \\
\hline Family move & 0.005 & - & 0 & 1 \\
\hline Education & 0.002 & - & 0 & 1 \\
\hline Marriage, divorce, widowhood & 0.016 & - & 0 & 1 \\
\hline Insecurity, disaster, or violence & 0.001 & - & 0 & 1 \\
\hline Other reason & 0.004 & - & 0 & 1 \\
\hline \multicolumn{5}{|l|}{ Migration distance } \\
\hline No migration & 0.966 & - & 0 & 1 \\
\hline Intra-state move & 0.029 & - & 0 & 1 \\
\hline Inter-state move & 0.005 & - & 0 & 1 \\
\hline \multicolumn{5}{|l|}{ Migration destination } \\
\hline No migration & 0.966 & - & 0 & 1 \\
\hline Rural destination & 0.022 & - & 0 & 1 \\
\hline Urban destination & 0.013 & - & 0 & 1 \\
\hline Age & 28.965 & 9.559 & 15 & 49 \\
\hline \multicolumn{5}{|l|}{ Sex } \\
\hline Male & 0.508 & - & 0 & 1 \\
\hline Female & 0.492 & - & 0 & 1 \\
\hline \multicolumn{5}{|l|}{ Education } \\
\hline Illiterate, less than primary & 0.453 & - & 0 & 1 \\
\hline Literate, less than primary & 0.098 & - & 0 & 1 \\
\hline Literate, primary + & 0.448 & - & 0 & 1 \\
\hline Unknown & 0.001 & - & 0 & 1 \\
\hline \multicolumn{5}{|l|}{ Religion } \\
\hline Hindu & 0.831 & - & 0 & 1 \\
\hline Muslim & 0.111 & - & 0 & 1 \\
\hline Christian & 0.025 & - & 0 & 1 \\
\hline Buddhist & 0.006 & - & 0 & 1 \\
\hline Other or Unknown & 0.027 & - & 0 & 1 \\
\hline \multicolumn{5}{|l|}{ Previous Residence } \\
\hline Rural & 0.783 & - & 0 & 1 \\
\hline Urban & 0.217 & - & 0 & 1 \\
\hline \multicolumn{5}{|l|}{ Year } \\
\hline 1983 & 0.285 & - & 0 & 1 \\
\hline 1987 & 0.304 & - & 0 & 1 \\
\hline 1999 & 0.410 & - & 0 & 1 \\
\hline$N$ & 933,627 & & & \\
\hline
\end{tabular}


Table 2: Logistic regression predicting the effect of climate on migration

\begin{tabular}{|c|c|c|}
\hline & $\begin{array}{l}\text { Model } 1 \\
\beta\end{array}$ & $\mathrm{SE}$ \\
\hline Temperature & -0.025 & $(0.034)$ \\
\hline Temperture $^{2}$ & $-0.078 *$ & $(0.038)$ \\
\hline Precipitation & -0.034 & $(0.030)$ \\
\hline Precipitation $^{2}$ & $-0.034 * * *$ & $(0.008)$ \\
\hline Age & $-0.061 *$ & $(0.027)$ \\
\hline Age-squared & -0.000 & $(0.000)$ \\
\hline Sex (female) & $0.805 * * *$ & $(0.081)$ \\
\hline \multicolumn{3}{|l|}{ Education } \\
\hline Literate, less than primary & -0.008 & $(0.057)$ \\
\hline Literate, primary + & $0.207^{*}$ & $(0.081)$ \\
\hline Unknown & -0.356 & $(0.327)$ \\
\hline \multicolumn{3}{|l|}{ Religion } \\
\hline Muslim & $-0.246 * * *$ & $(0.068)$ \\
\hline Christian & -0.014 & $(0.071)$ \\
\hline Buddhist & 0.0676 & $(0.041)$ \\
\hline Other, Unknown & -0.116 & $(0.126)$ \\
\hline Previous Residence (urban) & $0.246^{* * *}$ & $(0.028)$ \\
\hline \multicolumn{3}{|l|}{ Year } \\
\hline 1987 & -0.017 & $(0.051)$ \\
\hline 1999 & 0.019 & $(0.099)$ \\
\hline Joint test, temperature & 4.25 & \\
\hline Joint test, precipitation & $23.70 * * *$ & \\
\hline Joint test, climate variables & $32.32 * * *$ & \\
\hline $\mathrm{N}$ & 933,302 & \\
\hline Pseudo $\mathrm{R}^{2}$ & 0.063 & \\
\hline
\end{tabular}

Note: All models also include province fixed effects and controls.

Significance: $*<.05 * *<.01 * * *<.001$ 
Table 3: Logistic regression models predicting the probability of migration between rural - urban areas

\begin{tabular}{|c|c|c|c|c|}
\hline & \multicolumn{2}{|c|}{$\begin{array}{l}\text { Model } 2 \\
\text { Rural Destination }\end{array}$} & \multicolumn{2}{|c|}{\begin{tabular}{|l} 
Model 3 \\
Urban Destination
\end{tabular}} \\
\hline & $\beta$ & $\mathrm{SE}$ & $\beta$ & $\mathrm{SE}$ \\
\hline Temperature & -0.0705 & $(0.051)$ & 0.032 & $(0.054)$ \\
\hline Temperture $^{2}$ & $-0.120 * *$ & $(0.045)$ & 0.0041 & $(0.052)$ \\
\hline Precipitation & -0.0361 & $(0.034)$ & -0.035 & $(0.050)$ \\
\hline Precipitation $^{2}$ & -0.0145 & $(0.013)$ & $-0.057 * *$ & $(0.022)$ \\
\hline Temperature $*$ urban origin & 0.0598 & $(0.042)$ & -0.012 & $(0.050)$ \\
\hline Temperature $^{2} *$ urban origin & 0.0126 & $(0.038)$ & -0.012 & $(0.039)$ \\
\hline Precipitation $*$ urban origin & -0.0143 & $(0.066)$ & 0.025 & $(0.069)$ \\
\hline Precipitation $^{2} *$ urban origin & -0.0134 & $(0.035)$ & -0.035 & $(0.043)$ \\
\hline Age & $-0.129 * * *$ & $(0.036)$ & $0.057 * *$ & $(0.018)$ \\
\hline Age-squared & 0.001 & $(0.001)$ & $-0.002 * * *$ & $(0.000)$ \\
\hline Sex (female) & $1.117 * * *$ & $(0.126)$ & $0.373 * * *$ & $(0.044)$ \\
\hline \multicolumn{5}{|l|}{ Education } \\
\hline Literate, less than primary & $-0.175^{* *}$ & $(0.062)$ & $0.482 * * *$ & $(0.0756$ \\
\hline Literate, primary + & $-0.235 * * *$ & $(0.065)$ & $1.079 * * *$ & $(0.119)$ \\
\hline Unknown & $-1.083 *$ & $(0.517)$ & $0.818^{*}$ & $(0.357)$ \\
\hline \multicolumn{5}{|l|}{ Religion } \\
\hline Muslim & $-0.276 * *$ & $(0.107)$ & -0.184 & $(0.109)$ \\
\hline Christian & -0.051 & $(0.103)$ & 0.026 & $(0.084)$ \\
\hline Buddhist & 0.038 & $(0.0521)$ & $0.129 *$ & $(0.051)$ \\
\hline Other, Unknown & -0.038 & $(0.142)$ & -0.272 & $(0.223)$ \\
\hline Previous Residence (urban) & $-0.247 * * *$ & $(0.059)$ & $0.842 * * *$ & $(0.100)$ \\
\hline \multicolumn{5}{|l|}{ Year } \\
\hline 1987 & 0.032 & $(0.062)$ & -0.092 & $(0.068)$ \\
\hline 1999 & 0.209 & $(0.114)$ & $-0.290 * *$ & $(0.101)$ \\
\hline Joint test, temperature & $7.19 *$ & & 0.39 & \\
\hline Joint test, precipitation & 2.35 & & $6.97 *$ & \\
\hline Joint test, climate variables & 7.79 & & 7.11 & \\
\hline Joint test temp*urban $*$ urban*temp ${ }^{2}$ & 2.1 & & 0.66 & \\
\hline Joint test precip*urban, precip ${ }^{2 *}$ urban & 0.15 & & 0.68 & \\
\hline Joint test interaction terms & 2.11 & & 0.97 & \\
\hline Pseudo $\mathrm{R}^{2}$ & 0.079 & & & \\
\hline $\mathrm{N}$ & 933,302 & & & \\
\hline
\end{tabular}

Note: All models also include province fixed effects and controls.

Significance $*<.05 * *<.01 * * *<.001$ 
Table 4: Multinomial logistic regression models predicting the probability of migration by cause

\begin{tabular}{|c|c|c|c|c|c|c|c|c|}
\hline & \multirow{2}{*}{\multicolumn{2}{|c|}{$\begin{array}{l}\text { Model } 4 \\
\text { Labor Migration }\end{array}$}} & \multirow{2}{*}{\multicolumn{2}{|c|}{$\begin{array}{l}\text { Model } 5 \\
\text { Family-related } \\
\text { migration } \\
\end{array}$}} & \multirow{2}{*}{\multicolumn{2}{|c|}{$\begin{array}{l}\text { Model } 6 \\
\text { Marriage migration }\end{array}$}} & \multirow{2}{*}{\multicolumn{2}{|c|}{$\begin{array}{l}\text { Model } 7 \\
\text { Other migration }\end{array}$}} \\
\hline & & & & & & & & \\
\hline & $\beta$ & $(\mathrm{SE})$ & $\beta$ & $(\mathrm{SE})$ & $\beta$ & $(\mathrm{SE})$ & $\beta$ & $(\mathrm{SE})$ \\
\hline Temperature & -0.0611 & $(0.047)$ & 0.0233 & $(0.047)$ & -0.002 & $(0.050)$ & 0.079 & $(0.059)$ \\
\hline Temperature $^{2}$ & $-0.094 * *$ & $(0.034)$ & $-0.136^{* * *}$ & $(0.034)$ & -0.075 & $(0.050)$ & -0.013 & $(0.076)$ \\
\hline Precipitation & -0.010 & $(0.051)$ & 0.033 & $(0.054)$ & -0.017 & $(0.031)$ & -0.051 & $(0.075)$ \\
\hline Precipitation $^{2}$ & $-0.074 * * *$ & $(0.019)$ & -0.019 & $(0.027)$ & -0.000 & $(0.016)$ & -0.014 & $(0.030)$ \\
\hline Age & $0.232 * * *$ & $(0.020)$ & $0.104 * * *$ & $(0.015)$ & -0.041 & $(0.075)$ & -0.032 & $(0.039)$ \\
\hline $\mathrm{Age}^{2}$ & $-0.004 * * *$ & $(0.000)$ & $-0.002 * * *$ & $(0.000)$ & -0.003 & $(0.001)$ & -0.000 & $(0.001)$ \\
\hline Sex & $-1.697 * * *$ & $(0.135)$ & $1.890 * * *$ & $(0.069)$ & $3.746 * * *$ & $(0.145)$ & $-0.387 * * *$ & $(0.051)$ \\
\hline \multicolumn{9}{|l|}{ Education } \\
\hline $\begin{array}{l}\text { Literate, less than } \\
\text { primary }\end{array}$ & 0.038 & $(0.081)$ & $0.452 * * *$ & $(0.104)$ & $-0.169 *$ & $(0.073)$ & 0.021 & $(0.091)$ \\
\hline Literate, primary + & $0.377 * * *$ & $(0.112)$ & $0.831 * * *$ & $(0.093)$ & $-0.258 * * *$ & $(0.047)$ & $0.714 * * *$ & $(0.128)$ \\
\hline Unknown & 0.601 & $(0.551)$ & 0.226 & $(0.469)$ & $-1.214^{*}$ & $(0.498)$ & 0.075 & $(0.743)$ \\
\hline \multicolumn{9}{|l|}{ Religion } \\
\hline Muslim & $-0.389 * * *$ & $(0.084)$ & $-0.306 * * *$ & $(0.080)$ & -0.164 & $(0.091)$ & -0.273 & $(0.141)$ \\
\hline Christian & 0.188 & $(0.123)$ & -0.182 & $(0.120)$ & $-0.264 * *$ & $(0.092)$ & $0.171^{*}$ & $(0.067)$ \\
\hline Buddhist & $0.229 * * *$ & $(0.042)$ & $0.246 * * *$ & $(0.046)$ & -0.036 & $(0.072)$ & -0.019 & $(0.098)$ \\
\hline Other, Unknown & 0.068 & $(0.308)$ & -0.190 & $(0.195)$ & -0.010 & $(0.085)$ & $-0.666 * * *$ & $(0.147)$ \\
\hline $\begin{array}{l}\text { Previous Residence } \\
\text { (rban) }\end{array}$ & $0.552 * * *$ & $(0.057)$ & $0.759 * * *$ & $(0.067)$ & $-0.473 * * *$ & $(0.046)$ & $0.611 * * *$ & $(0.100)$ \\
\hline \multicolumn{9}{|l|}{ Year } \\
\hline 1987 & -0.138 & $(0.087)$ & -0.043 & $(0.053)$ & $0.158 * *$ & $(0.061)$ & -0.109 & $(0.102)$ \\
\hline 1999 & $-0.400 * * *$ & $(0.074)$ & $-0.278 * *$ & $(0.095)$ & $0.481 * * *$ & $(0.145)$ & -0.234 & $(0.162)$ \\
\hline $\begin{array}{l}\text { Joint test, } \\
\text { temperature }\end{array}$ & $7.80 *$ & & $22.43 * * *$ & & 2.35 & & 2.10 & \\
\hline $\begin{array}{l}\text { Joint test, } \\
\text { precipitation }\end{array}$ & $16.61 * * *$ & & 1.47 & & 0.46 & & 0.48 & \\
\hline $\begin{array}{l}\text { Joint test, climate } \\
\text { variables }\end{array}$ & $26.61 * * *$ & & $23.93 * * *$ & & 2.58 & & 5.42 & \\
\hline Pseudo $\mathrm{R}^{2}$ & 0.11 & & 0.07 & & 0.14 & & 0.07 & \\
\hline $\mathrm{N}$ & 933,302 & & 933,302 & & 933,302 & & 933,302 & \\
\hline
\end{tabular}

Note: All models also include province fixed effects.

Significance: $*<.05 * *<.01 * * *<.001$ 
Table 5: Logistic regression predicting the effect of climate on migration with sex interactions

\begin{tabular}{|c|c|}
\hline Temperature & $0.118 * *$ \\
\hline Temperature $^{2}$ & $-0.133 * *$ \\
\hline Precipitation & -0.0431 \\
\hline Precipitation $^{2}$ & -0.0468 \\
\hline \multicolumn{2}{|l|}{ Sex interactions (female) } \\
\hline Temperature & $-0.213 * *$ \\
\hline Temperature $^{2}$ & 0.0739 \\
\hline Precipitation & 0.0162 \\
\hline Precipitation $^{2}$ & 0.0191 \\
\hline Joint test sex $*$ temperature & $13.55^{* *}$ \\
\hline Joint test sex $*$ precipitation & 0.39 \\
\hline Join test, all interaction terms & $38.10 * * *$ \\
\hline Pseudo $\mathrm{R}^{2}$ & 0.064 \\
\hline $\mathrm{N}$ & 933,302 \\
\hline
\end{tabular}

Model 8

Migration

$\beta \quad(\mathrm{SE})$

$0.118^{* *} \quad(0.0453)$

$-0.133 * * \quad(0.0441)$

Precipitation $^{2}$

$(0.0241)$

ex interactions (female)

$0.213 * * * \quad(0.0582)$

$(0.0463)$

$(0.0670)$

Notes: All models also include province fixed effects and controls.

Significance: $*<.05 * *<.01 * * *<.001$ 
Table 6: Logistic regression models predicting the probability of migration between rural - urban areas with sex interactions

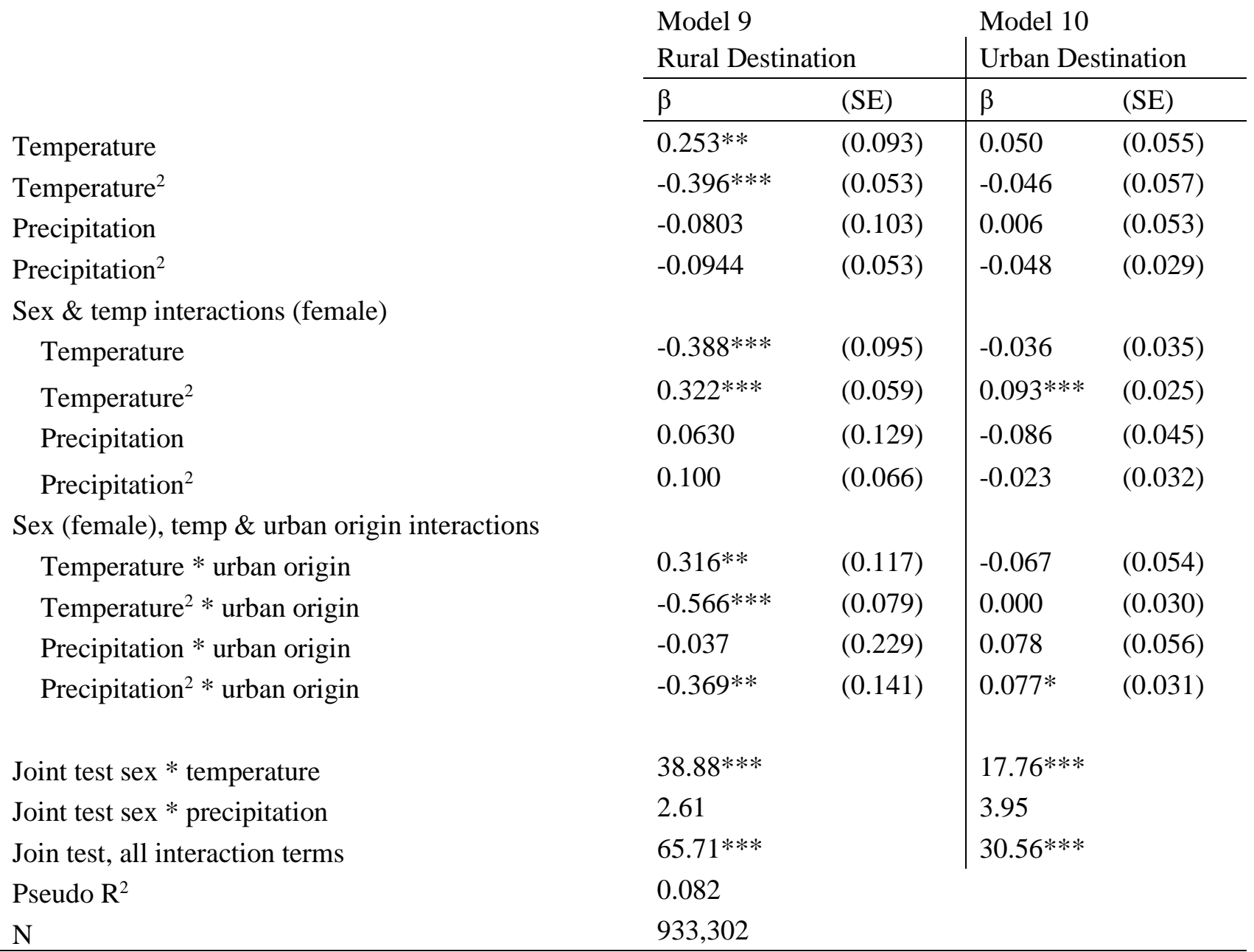

Notes: All models also include province fixed effects and controls.

Significance $*<.05 * *<.01 * * *<.001$ 
Table 7: Multinomial logistic regression models predicting the probability of migration by cause with sex interactions

\begin{tabular}{|c|c|c|c|c|c|c|c|c|}
\hline & \multicolumn{2}{|c|}{$\begin{array}{l}\text { Model } 11 \\
\text { Labor Migration }\end{array}$} & \multicolumn{2}{|c|}{$\begin{array}{l}\text { Model } 12 \\
\text { Family-related } \\
\text { migration }\end{array}$} & \multicolumn{2}{|c|}{$\begin{array}{l}\text { Model } 13 \\
\text { Marriage migration }\end{array}$} & \multicolumn{2}{|c|}{$\begin{array}{l}\text { Model } 14 \\
\text { Other migration }\end{array}$} \\
\hline & $\beta$ & (SE) & $\beta$ & (SE) & $\beta$ & $(\mathrm{SE})$ & $\beta$ & (SE) \\
\hline Temperature & -0.081 & $(0.051)$ & 0.109 & $(0.070)$ & $0.258 * *$ & $(0.080)$ & 0.085 & $(0.047)$ \\
\hline Temperature $^{2}$ & $-0.084 *$ & $(0.039)$ & $-0.154 * *$ & $(0.057)$ & -0.197 & $(0.118)$ & -0.003 & $(0.071)$ \\
\hline Precipitation & 0.0086 & $(0.055)$ & 0.050 & $(0.069)$ & -0.033 & $(0.162)$ & -0.058 & $(0.084)$ \\
\hline $\begin{array}{l}\text { Precipitation }{ }^{2} \\
\text { Sex interactions } \\
\text { (female) }\end{array}$ & $-0.061 * * *$ & $(0.018)$ & -0.095 & $(0.078)$ & $0.175^{*}$ & $(0.087)$ & -0.017 & $(0.033)$ \\
\hline Temperature & 0.204 & $(0.131)$ & $-0.107^{*}$ & $(0.049)$ & $-0.265 * * *$ & $(0.068)$ & -0.011 & $(0.070)$ \\
\hline Temperature $^{2}$ & -0.106 & $(0.099)$ & 0.021 & $(0.044)$ & 0.124 & $(0.109)$ & -0.028 & $(0.055)$ \\
\hline Precipitation & -0.160 & $(0.105)$ & -0.018 & $(0.071)$ & 0.017 & $(0.170)$ & 0.019 & $(0.061)$ \\
\hline Precipitation $^{2}$ & -0.111 & $(0.080)$ & 0.089 & $(0.087)$ & $-0.182 *$ & (0.089) & 0.006 & $(0.035)$ \\
\hline $\begin{array}{l}\text { Joint test sex } * \\
\text { temperature }\end{array}$ & $12.69 *$ & & $23.76^{* * *}$ & & $15.60 * *$ & & 7.27 & \\
\hline $\begin{array}{l}\text { Joint test sex } * \\
\text { precipitation }\end{array}$ & $17.21 * *$ & & 3.13 & & $10.56^{*}$ & & 0.53 & \\
\hline $\begin{array}{l}\text { Join test, all interaction } \\
\text { terms }\end{array}$ & $38.44 * * *$ & & $36.05 * * *$ & & $103.04 * * *$ & & 11.70 & \\
\hline Psuedo $\mathrm{R}^{2}$ & 0.110 & & 0.068 & & 0.140 & & 0.0719 & \\
\hline $\mathrm{N}$ & 933,302 & & 933,302 & & 933,302 & & 933,302 & \\
\hline
\end{tabular}

Note: All models also include province fixed effects and controls.

Significance $*<.05 * *<.01 * * *<.001$ 


\section{Appendix}

Table 8: Logistic regression predicting the effect of climate on migration without temperature and precipitation squared terms

\begin{tabular}{|c|c|c|}
\hline & $\beta$ & SE \\
\hline Temperature & -0.002 & $(0.036)$ \\
\hline Precipitation & -0.036 & $(0.035)$ \\
\hline Age & $-0.0607 *$ & $(0.027)$ \\
\hline Age-squared & -0.000 & $(0.000)$ \\
\hline Sex (female) & $0.805^{* * *}$ & $(0.081)$ \\
\hline \multicolumn{3}{|l|}{ Education } \\
\hline Literate, less than primary & -0.008 & $(0.057)$ \\
\hline Literate, primary + & $0.206^{*}$ & $(0.081)$ \\
\hline Unknown & -0.364 & $(0.328)$ \\
\hline \multicolumn{3}{|l|}{ Religion } \\
\hline Muslim & $-0.246 * * *$ & $(0.068)$ \\
\hline Christian & -0.012 & $(0.071)$ \\
\hline Buddhist & 0.070 & $(0.041)$ \\
\hline Other, Unknown & -0.115 & $(0.126)$ \\
\hline Previous Residence (urban) & $0.246 * * *$ & $(0.028)$ \\
\hline \multicolumn{3}{|l|}{ Year } \\
\hline 1987 & -0.043 & $(0.050)$ \\
\hline 1999 & -0.064 & $(0.064)$ \\
\hline Joint test, climate variables & 1.34 & \\
\hline $\mathrm{N}$ & 933302 & \\
\hline Pseudo $\mathrm{R}^{2}$ & 0.0627 & \\
\hline
\end{tabular}

Note: $*<.05 * *<.01 * * *<.001$ 
Table 9: Logistic regression models predicting the probability of migration between rural - urban areas from rural origin

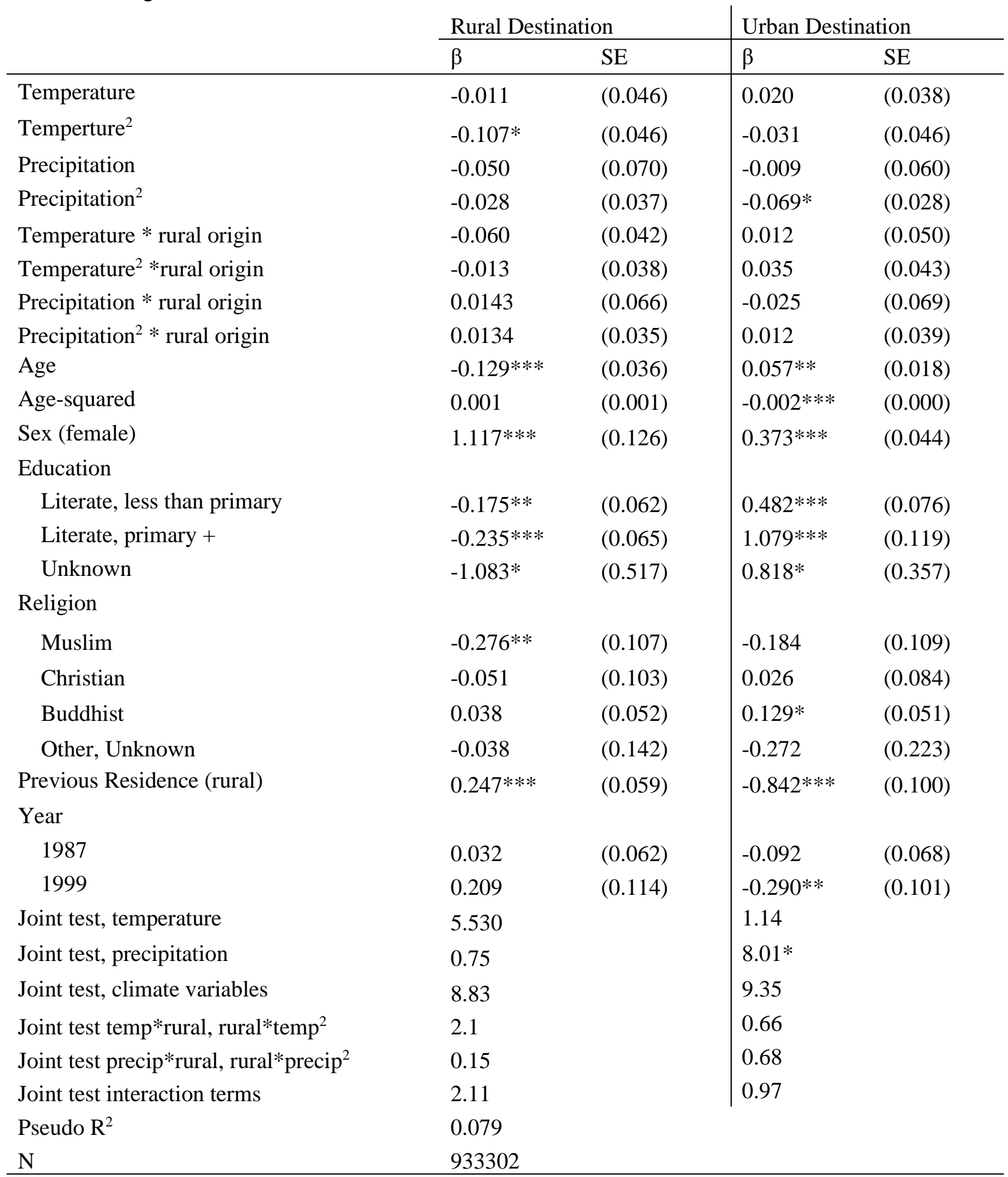

Significance $*<.05 * *<.01 * * *<.001$ 